\title{
A Study of Intrinsic Leisure Motivation among Prospective Teachers in relations to their Academic Achievement
}

\author{
Anjum Ahmed* and Saeed Abdur Rouf \\ Department of Education, Aligarh Muslim University, Aligarh, India \\ "Corresponding author: anjum.amu1312@gmail.com
}

Received: 03-01-2021 Revised: 15-02-2021 Accepted: 02-03-2021

\begin{abstract}
Teachers are the prime agents in bringing about social change. This huge responsibility is resting on teachers' shoulders, and as a result, it makes this profession a very demanding career. Even teachers require leisure-time. They need to be recreationally motivated, which includes fulfilling personal goals such as the need for affiliation, liberation from stress or the boredom of daily routines, and the pursuit for a challenge. For this study, the tool used was the Intrinsic Leisure Motivation scale (ILM) developed by Ellen Weissinger and Deborah L. Bandalos (1995). The sample of the study consisted of 92 prospective teachers from Aligarh Muslim University. The analysis revealed that the Intrinsic Leisure Motivation of prospective teachers had scores above the average. Intrinsic Leisure Motivation sub-dimensions like selfdetermination, challenge and competence had almost the same highest mean while commitment had the least mean. A significant difference was found in favour of prospective male teachers in the Intrinsic Leisure Motivation (on sub-dimensions like self-determination, commitment and challenge). Another finding of this study was that no significant difference was found in rural and urban prospective teachers' mean scores. Lastly, the sample under study did not share a meaningful relationship between Intrinsic Leisure Motivation (with its respective sub-dimensions)and academic achievement. The educational implications have been drawn and discussed, according to the findings, in the research paper.
\end{abstract}

Keywords: Intrinsic leisure motivation, self-determination, challenge, competence, commitment, prospective teachers

\section{Intrinsic Leisure Motivation}

Intrinsic leisure motivation occurs when one act without any obvious external rewards. It is when we simply enjoy an activity or see it as a means to explore, learn, and actualize our potentials. Intrinsic leisure motivation is an essential topic in education. Instructional or curriculum designers and teachers aim to develop intrinsically, rewarding learning environments. Unfortunately, many traditional paradigms suggest that most students find learning boring so they must be extrinsically instigated into educational activities.

In "Making Learning Fun: A Taxonomy of Intrinsic leisure Motivations for Learning," authors Thomas Malone and Mark Leeper (1987) suggested that this does not need to be the case that is, how students are extrinsically coerced into educational activities because of boredom. In fact they identified several different ways to make learning environments that are intrinsically rewarding.

Activities are intrinsically motivating if "people engage in it for its own sake, rather than in order to receive some external reward or avoid some external punishment." The words enjoyable,fun, captivating,engaging, and intrinsically motivating

\footnotetext{
How to cite this article: Ahmed, A. and Rouf, S.A. 2021. A Study of Intrinsic Leisure Motivation among Prospective Teachers in relations to their Academic Achievement. Educational Quest: An Int. J. Edu. Appl. Soc. Sci., 12(1): 14-27.

Source of Support: None; Conflict of Interest: None (2)
} 
are used synonymously to describe such activities. The factors they established as increasing intrinsic leisure motivation include:

* Control: When we want to control ourselves and our environment and want to determine what we pursue.

* Challenge: When one is motivated to pursue goals with personal meaning. These goals may also relate to ones' self-esteem when performance feedback is available.

* Curiosity: Includes Sensory Curiosity, that is, when internal motivation is increased when something in the physical environment grabs the individual's attention. And Cognitive Curiosity is when something about the activity stimulates the person to want to learn more.

* Cooperation and competition: Intrinsic motivation can be added or enhanced in circumstances where people gain satisfaction from helping others. It is also applicable in cases where they can compare their performance favorably to that of others.

* Recognition: People enjoy having their triumph and accomplishment recognized by others; this boost up their internal motivation.

Motivation is defined as an impulse that sets people directly in motion and generally displays an intrinsic behaviour. David McClelland was the first one to conduct studies on achievement motivation. His theory defines achievement motivation as awarding people for their acts under suitable conditions (McClelland, 1961; McClelland and Winter, 1969). Weiner (1986) proposed achievement motivation as the most assertive attribution theory on feelings. This theory concerns the causal thinking characteristics and subsequent emotional experiences perceived by the reasons for success and failure. Another critical attribution theory on motivation is the goal orientation theory. The pillar of achievement goal orientation theory is that students determine their academic orientation based on their various personal goals. Several factors affect the academic orientation of students (Elliot and McGregor, 2001).

The concept of motivation has been studied from several viewpoints (like- Freud, 1923/1962; Hull, 1943; Skinner, 1953). One frame of reference which has proven useful over the past two decades suggests that behaviour can be seen as intrinsically or extrinsically motivated (De Charms, 1968; Deci, 1971, 1975). Intrinsically motivated behaviours are those that are engaged in for their own sake, particularly for the pleasure and satisfaction derived from performing them (Deci, 1971). They are activities that people intentionally perform in the absence of material rewards or constraints (Deci \& Ryan, 1985).

To read a book for the sheer pleasure of learning something interesting is an example of intrinsic motivation. On the other hand, extrinsic motivation pertains to a wide variety of behaviours where the goals of action extend beyond those ingrained in the activity itself. They are behaviours that are engaged in as means to an end and not for their sakes (Deci, 1975; Kruglanski, 1978). More recently, researchers (Deci \& Ryan 1987; Ryan \& Connell, 1989; Ryan, Connell \& Deci, 1985) have proposed that different types of extrinsic motivation exist, some of which are self-determined and may be performed through self-regulation.

Apart from intrinsic and extrinsic motivation, Deci and Ryan (1985) claim that a third construct, amotivation, must be considered to understand human behaviour comprehensively. Individuals are amotivated when they perceive a lack of contingency between their behaviour and outcomes. There is an experience of incompetence and lack of control. Amotivated behaviours are neither intrinsically nor extrinsically motivated: They are non-motivated.

More recently, researchers have focused on the consequences and correlates of intrinsic motivation. Such researches revealed that situational events known to facilitate intrinsic motivation produce greater interest (Ryan, Mims, \& Koestner, 1983), better conceptual learning (Grolnick \& Ryan, 1987), more cognitive flexibility (McGraw \& McCullers, 1979), more creativity (Amabile, Hennessey, \& Grossman, 1986), and a more positive emotional tone (Garbarino, 1975) than events known to be controlling.

\section{Significance of the study}

In general, everyone wants to be happy. Happiness is a recurring positive effect, high life satisfaction, and sporadic negative affect. Persons high in this intrinsic motivation component tend to want 
to feel in control of their leisure behaviour and exhibit an enhanced degree of wilfulness. Beyond the familiar motivations of seeking fun, pleasure, or relaxation, people engage in leisure pursuits for a number of various reasons. Understanding what motivates student participation in campus recreational programs may capacitate the oncampus recreation professionals to design better programs that augment student activities. The emotional motivators involve happiness, fun, intellectual outcomes, and spiritual values. Leisure can bring all of these rewards to a person. Persons high in intrinsic motivation orientation become involved in more clearly intended behaviours and interact with the environment directly. Teachers are the prime agents in bringing about social change. This huge responsibility is resting on teachers' shoulders, and as a result, it makes this profession a very demanding career. Even teachers require leisure-time. They need to be recreationally motivated, which includes fulfilling personal goals such as the need for affiliation, liberation from stress or the boredom of daily routines, and the pursuit for a challenge. With the help of a review of related studies on intrinsic motivation, the researchers were tempted to study the variable intrinsic leisure motivations in university students, especially among prospective teachers. Besides, the study anticipated to determine the relationship between intrinsic leisure motivations, its sub-dimensions and academic achievement.

Based on the findings of the present research, the contribution of leisure to the development of mind and body that had such relevance during ancient times continues to be relevant today. One of the essential factors that boost and sustain individuals' participation in leisure activities is their motivation. Given the significance of motivation on participation and the positive outcomes associated with leisure and recreational activities, motivation within recreation has been well examined previously. The researches, as mentioned above, have been done on various dimensions like intrinsic leisure motivation, Leisure participation, Prospective teacher's performance, Academic Achievement etc. Despite the wealth of research on intrinsic leisure motivation at the beginning of the $21^{\text {st }}$ century, a noticeable gap can easily be seen in the research after 1993.
Moreover, none of the studies have been conducted in the Indian context. So the purpose of this study is to throw light on this crucial variable, i.e., intrinsic leisure motivation. For this, the researchers intended to explore the relationship between intrinsic leisure motivation and academic achievement. The sample selected was the prospective teachers studying at Aligarh Muslim University. The study also aimed to address the information regarding leisure time and how to develop the sense of pursuing their leisure time which could benefit us in our professional life too.

\section{Research Questions}

What is the Intrinsic Leisure Motivation of the sample under study?

$\square$ Whether there is any significant relationship between Intrinsic Leisure Motivation (with its respective sub-dimensions) and academic achievement among prospective teachers?

$\square$ Is there a gender difference in Intrinsic Leisure Motivation?

$\square$ Do respondents of different locality differ in their Intrinsic Leisure Motivation?

\section{Objectives of the study}

The objectives formulated for the study are:

1. To find out the Intrinsic Leisure Motivation (with its respective sub-dimensions) in the total sample

2. To explore the relationship between Intrinsic Leisure Motivation (with its respective subdimensions) and academic achievement among prospective teachers.

3. To find out the significant difference in the mean scores of Intrinsic Leisure Motivation (with its respective sub-dimensions) between prospective male and female teachers.

4. To find out the significant difference in the mean scores of Intrinsic Leisure Motivation (with its respective sub-dimensions) between rural and urban prospective teachers.

\section{Tools used}

In order to collect data for the present study, the following tool was used: Intrinsic Leisure Motivation scale (ILM) developed by Ellen Weissinger and 
Deborah L. Bandalos (1995). Based on the conceptual work of Deci and Ryan (1985), Kobasa (1979), and their associates, the intrinsic leisure motivation disposition and its four components are defined as:

Intrinsic Leisure Motivation Disposition: is a tendency to seek intrinsic rewards in leisure behaviour. It is assumed that the strength of this tendency will differ across individuals but will be relatively stable within individuals and across situations. The following conceptual definitions of intrinsic leisure motivation have components/sub-dimensions such as Self-Determination, Competence, Commitment and Challenge.

The Intrinsic Leisure Motivation (ILM) Scale consisted of 24 items. The scale utilized as evenpoint response range $(1=$ Very Strongly Disagree to 7 = Very Strongly Agree). As the scale was adapted, it was pre-tested on 40 respondents from Aligarh Muslim University. After pretesting, necessary modifications (reframing of the statements) were made to the scale to fit it for the present study. Finally, the questionnaire was checked by the reliability test. The Cronbach's Alpha value was re-established as 0.84 .

\section{Sample of the Study}

The sample of the study consisted of 92 prospective teachers (39 Male and 53 Female). The entire sample was collected from Aligarh Muslim University,
Aligarh. The sample was selected through stratified random sampling according to the different streams of prospective teachers.

Table 1: Frequency and percentage of demographic variables

\begin{tabular}{llll}
\hline $\mathbf{N = ( 9 2 )}$ & Groups & Frequency & $\mathbf{\%}$ \\
\hline \multirow{2}{*}{ Gender } & Male & 39 & 42.4 \\
& Female & 53 & 57.6 \\
\multirow{2}{*}{ Locality } & Rural & 23 & 25.0 \\
& Urban & 69 & 75.0 \\
& Between 6.0-7.0 & 13 & 14.13 \\
CGPA & Between 7.1-8.0 & 41 & 44.57 \\
& Above 8.1 & 38 & 41.30 \\
\hline
\end{tabular}

Objective 1: To find out the Intrinsic Leisure Motivation (with its respective sub-dimensions) in the total sample.

The result of descriptive analysis is presented in table 2. It was determined that Intrinsic Leisure Motivation average scores for this sample of prospective teachers are $(90.02 \pm 8.42)$ in which the sub-dimensions like self-determination, challenge and competence had almost the same mean $(\mathrm{M}=23, \mathrm{M}$ $=23.1$ and $\mathrm{M}=23.3$ respectively). Commitment subdimension had the lowest mean $(20.7 \pm 2.90)$.

The prospective male teachers scored above average on that Intrinsic Leisure Motivation (93.38

Table 2: Mean and Standard deviation values of Intrinsic Leisure Motivation (with its respective sub-dimensions) in the total sample

\begin{tabular}{|c|c|c|c|c|c|}
\hline Variable & Minimum & Maximum & Sample & Mean & Standard Deviation \\
\hline \multirow[t]{3}{*}{ Self-Determination } & 14 & 28 & Total (92) & 23 & 2.87 \\
\hline & & & Male (39) & 23.69 & 2.35 \\
\hline & & & Female (53) & 22.49 & 3.12 \\
\hline \multirow[t]{3}{*}{ Commitment } & 13 & 29 & Total (92) & 20.7 & 2.90 \\
\hline & & & Male (39) & 21.74 & 2.68 \\
\hline & & & Female (53) & 19.90 & 2.83 \\
\hline \multirow[t]{3}{*}{ Challenge } & 14 & 30 & Total (92) & 23.1 & 3.18 \\
\hline & & & Male (39) & 23.97 & 2.42 \\
\hline & & & Female (53) & 22.43 & 3.52 \\
\hline \multirow[t]{3}{*}{ Competence } & 14 & 30 & Total (92) & 23.3 & 3.17 \\
\hline & & & Male (39) & 23.97 & 2.48 \\
\hline & & & Female (53) & 22.71 & 3.51 \\
\hline \multirow{3}{*}{$\begin{array}{l}\text { Total Intrinsic Leisure } \\
\text { Motivation }\end{array}$} & 67 & 112 & Total (92) & 90.02 & 8.42 \\
\hline & & & Male (39) & 93.38 & 5.03 \\
\hline & & & Female (53) & 87.54 & 9.53 \\
\hline
\end{tabular}


\pm 5.03 ), and the prospective female teachers score on Intrinsic Leisure Motivation was well below the total's and male's mean scores $(87.54 \pm 9.53)$. The difference in the average score of the male and female remained constant in the three subdimension self-determination, challenge, commitment. In which male had the edge over the prospective female teachers. In commitment sub-dimension, the average difference was more evident between prospective male $(\mathrm{M}=21.74)$ and female teachers $(\mathrm{M}=19.90)$.

Objective 2: To explore the relationship between Intrinsic Leisure Motivation (with its respective sub-dimensions) and academic achievement among prospective teachers.

Table 3 displays the correlation matrix that shows the strength of the relationship between Intrinsic Leisure Motivation (its sub-dimensions) and Academic Achievement. The result revealed that there is no significant relationship between
Intrinsic Leisure Motivation (with its respective sub-dimensions)and academic achievement among prospective teachers, $\mathrm{r}(90)=.158, \mathrm{p}=.133$. On further analysis, it was revealed that all the subdimensions of Intrinsic Leisure Motivation strongly correlated with the total score of Intrinsic Leisure Motivation. Competence sub-dimension shared the strongest significant positive correlation with Intrinsic Leisure Motivation $\mathrm{r}(90)=.784, \mathrm{p}=.000$ and, the Commitment sub-dimension shared the least significant positive correlation with Intrinsic Leisure Motivation $r(90)=.617, p=.000$. Hence the null hypothesis that 'there will be no significant relationship between Intrinsic Leisure Motivation (with its respective sub-dimensions)and academic achievement among prospective teachers' is accepted.

Objective 3: To find out the significant difference in the mean scores of Intrinsic Leisure Motivation (with its respective sub-dimensions) between prospective male and female teachers.

Table 3: Pearson correlation matrix between Intrinsic Leisure Motivation (with its respective sub-dimensions) and academic achievement in the total sample

\begin{tabular}{|c|c|c|c|c|c|c|c|}
\hline & & 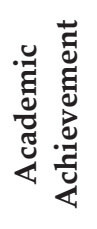 & 岕 & 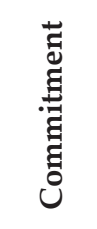 & 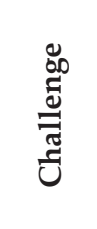 & 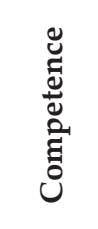 & 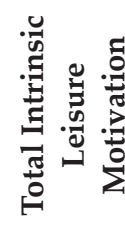 \\
\hline \multirow{4}{*}{ Academic Achievement } & Pearson Correlation & 1 & .151 & .110 & .011 & .172 & .158 \\
\hline & Sig. (2-tailed) & & .151 & .298 & .920 & .102 & .133 \\
\hline & $\mathrm{N}$ & 92 & 92 & 92 & 92 & 92 & 92 \\
\hline & Pearson Correlation & .151 & 1 & .143 & $.339^{* *}$ & $.326^{* *}$ & $.641^{* *}$ \\
\hline \multirow[t]{2}{*}{ Self Determination } & Sig. (2-tailed) & .151 & & .173 & .001 & .002 & .000 \\
\hline & $\mathrm{N}$ & 92 & 92 & 92 & 92 & 92 & 92 \\
\hline \multirow{3}{*}{ Commitment } & Pearson Correlation & .110 & .143 & 1 & .203 & $.391^{* *}$ & $.617^{* *}$ \\
\hline & Sig. (2-tailed) & .298 & .173 & & .053 & .000 & .000 \\
\hline & $\mathrm{N}$ & 92 & 92 & 92 & 92 & 92 & 92 \\
\hline \multirow{3}{*}{ Challenge } & Pearson Correlation & .011 & $.339^{* *}$ & .203 & 1 & $.427^{* *}$ & $.724^{* *}$ \\
\hline & Sig. (2-tailed) & .920 & .001 & .053 & & .000 & .000 \\
\hline & $\mathrm{N}$ & 92 & 92 & 92 & 92 & 92 & 92 \\
\hline \multirow{3}{*}{ Competence } & Pearson Correlation & .172 & $.326^{* *}$ & $.391^{* *}$ & $.427^{* *}$ & 1 & $.784^{* *}$ \\
\hline & Sig. (2-tailed) & .102 & .002 & .000 & .000 & & .000 \\
\hline & $\mathrm{N}$ & 92 & 92 & 92 & 92 & 92 & 92 \\
\hline \multirow{3}{*}{$\begin{array}{l}\text { Total Intrinsic Leisure } \\
\text { Motivation }\end{array}$} & Pearson Correlation & .158 & $.641^{* *}$ & $.617^{* *}$ & $.724^{* *}$ & $.784^{* *}$ & 1 \\
\hline & Sig. (2-tailed) & .133 & .000 & .000 & .000 & .000 & \\
\hline & $\mathrm{N}$ & 92 & 92 & 92 & 92 & 92 & 92 \\
\hline
\end{tabular}

**. Correlation is significant at the 0.01 level (2-tailed). 
Table 4: Mean score and t-test score of Intrinsic Leisure Motivation (with its respective subdimensions) between female and male prospective teachers

\begin{tabular}{llllll}
\hline Variables & Gender & N & Mean & SD & SE M \\
\hline Self- & Male & 39 & 23.6923 & 2.35253 & .37671 \\
Determination & Female & 53 & 22.4906 & 3.12941 & .42986 \\
& Male & 39 & 21.7436 & 2.68248 & .42954 \\
Commitment & Female & 53 & 19.9057 & 2.83701 & .38969 \\
& Male & 39 & 23.9744 & 2.42234 & .38789 \\
Challenge & Female & 53 & 22.4340 & 3.52196 & .48378 \\
& Male & 39 & 23.9744 & 2.48667 & .39819 \\
Competence & Female & 53 & 22.7170 & 3.51577 & .48293 \\
Total Intrinsic & Male & 39 & 93.3846 & 5.03992 & .80703 \\
Leisure & Female & 53 & 87.5472 & 9.53247 & 1.30939 \\
Motivation & & & & & \\
\hline
\end{tabular}

Tables 4 and 5 indicates the descriptive statistics and $\mathrm{t}$-value computed for the male and female subsample. The findings revealed that the prospective male teachers had a relatively high score on the Intrinsic Leisure Motivation scale than that of prospective female teachers $(M=93.38$ versus $M=$ 87.54). When the sub-dimensions were investigated, it was observed that prospective male teachers had scored more than prospective female teachers in all the sub-dimensions with similar mean difference except in the case of Commitment sub-dimension where the mean difference between prospective male and female teachers was the highest (MD = 1.84).

An independent t-test analysis was assessed, and it extrapolated the result that Intrinsic Leisure Motivation was associated with a statistically significant effect, $t(90)=3.38, p=.001$. Thus, the prospective male teacher statistically differed from the prospective female teachers in having the larger mean $(\mathrm{M}=93.38$ versus $\mathrm{M}=87.54)$. Therefore the null hypothesis 'there will be no significant difference in the mean scores of Intrinsic Leisure Motivation (with its respective sub-dimensions) between prospective male and female teachers' is rejected.

Dimensions-wise t-test analysis highlighted that prospective male teachers had statistically significant mean score than prospective female teachers in dimensions like Self-determination, where the t-vale

Table 5: Independent Samples Test

\begin{tabular}{|c|c|c|c|c|c|c|c|c|}
\hline & & $\begin{array}{l}\text { Lever } \\
\text { for Eq } \\
\text { Var }\end{array}$ & $\begin{array}{l}\text { 's Test } \\
\text { ality of } \\
\text { nces }\end{array}$ & & & t for Equa & of Means & \\
\hline & & $\mathbf{F}$ & Sig. & $\mathbf{T}$ & Df & $\begin{array}{l}\text { Sig. } \\
\text { (2-tailed) }\end{array}$ & $\begin{array}{l}\text { Mean } \\
\text { Difference }\end{array}$ & $\begin{array}{l}\text { Std. Error } \\
\text { Difference }\end{array}$ \\
\hline Self- & $\begin{array}{l}\text { Equal variances } \\
\text { assumed }\end{array}$ & 2.029 & .158 & 2.015 & 90 & .047 & 1.20174 & .59653 \\
\hline Determination & $\begin{array}{l}\text { Equal variances } \\
\text { not assumed }\end{array}$ & & & 2.103 & 89.945 & .038 & 1.20174 & .57156 \\
\hline Commitmont & $\begin{array}{l}\text { Equal variances } \\
\text { assumed }\end{array}$ & .874 & .352 & 3.142 & 90 & .002 & 1.83793 & .58498 \\
\hline comimatanemat & $\begin{array}{l}\text { Equal variances } \\
\text { not assumed }\end{array}$ & & & 3.169 & 84.476 & .002 & 1.83793 & .57997 \\
\hline Chollonor & $\begin{array}{l}\text { Equal variances } \\
\text { assumed }\end{array}$ & 6.475 & .013 & 2.351 & 90 & .021 & 1.54040 & .65518 \\
\hline cnallenge & $\begin{array}{l}\text { Equal variances } \\
\text { not assumed }\end{array}$ & & & 2.484 & 89.649 & .015 & 1.54040 & .62008 \\
\hline Compotons & $\begin{array}{l}\text { Equal variances } \\
\text { assumed }\end{array}$ & 2.435 & .122 & 1.908 & 90 & .060 & 1.25738 & .65884 \\
\hline competence & $\begin{array}{l}\text { Equal variances } \\
\text { not assumed }\end{array}$ & & & 2.009 & 89.887 & .048 & 1.25738 & .62592 \\
\hline Total Intrinsic & $\begin{array}{l}\text { Equal variances } \\
\text { assumed }\end{array}$ & 12.539 & .001 & 3.480 & 90 & .001 & 5.83745 & 1.67754 \\
\hline Motivation & $\begin{array}{l}\text { Equal variances } \\
\text { not assumed }\end{array}$ & & & 3.795 & 82.684 & .000 & 5.83745 & 1.53811 \\
\hline
\end{tabular}


computed is $\mathrm{t}(90)=2.015, \mathrm{p}=.047 ;$ Commitment $\mathrm{t}(90)$ $=3.142, \mathrm{p}=.002$ and Challenge $\mathrm{t}(90)=2.351, \mathrm{p}=.021$.

Objective 4: To find out the significant difference in the mean scores of Intrinsic Leisure Motivation (with its respective sub-dimensions) between rural and urban prospective teachers.

Data tabulated in table 6 and 7 highlights the descriptive statistics and t-test analysis of rural and urban prospective teachers. According to table 7, the descriptive statistics computed for rural and urban sub-sample revealed that the rural prospective teachers had a relatively high score on the Intrinsic Leisure Motivation scale than that of prospective urban teachers $(M=91.73$ versus $M=87.44)$. When the sub-dimensions were further analysed, it was observed that rural prospective teachers had scores higher than prospective urban teachers in all the sub-dimensions-Self-determination, Commitment and Challenge except in Competence were both the sub-

Table 6: Mean score and t-test score of Intrinsic Leisure Motivation (with its respective sub-dimensions) between rural and urban prospective teachers.

\begin{tabular}{llllll}
\hline Variables & Locality & N & Mean & Std. Deviation & Std. Error Mean \\
\hline \multirow{2}{*}{ Self-Determination } & Rural & 23 & 23.5217 & 2.59141 & .54035 \\
\multirow{3}{*}{ Commitment } & Urban & 69 & 22.8261 & 2.96031 & .35638 \\
& Rural & 23 & 21.4348 & 3.13087 & .65283 \\
Challenge & Urban & 69 & 20.4348 & 2.80482 & .33766 \\
& Rural & 23 & 23.6957 & 2.77054 & .57770 \\
Competence & Urban & 69 & 22.8841 & 3.30123 & .39742 \\
\multirow{2}{*}{ Total Intrinsic Leisure Motivation } & Rural & 23 & 23.0870 & 2.37244 & .49469 \\
& Urban & 69 & 23.3043 & 3.40546 & .40997 \\
& Rural & 23 & 91.7391 & 6.21009 & 1.29489 \\
& Urban & 69 & 89.4493 & 9.00741 & 1.08436 \\
\hline
\end{tabular}

Source: Results drawn from Survey Data.

Table 7: Independent Samples Test

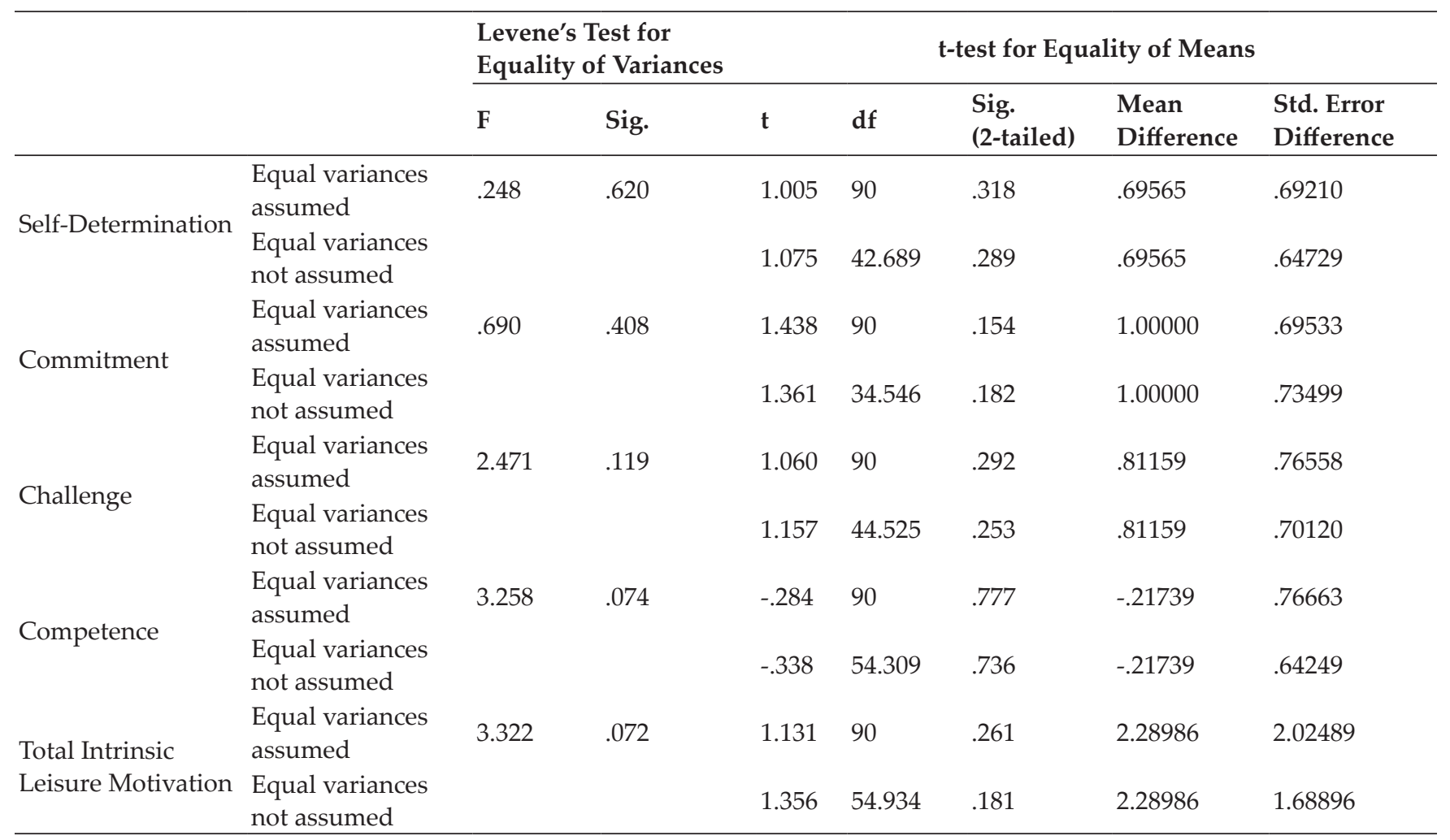

Source: Results drawn from Survey Data. 
samples scored similar average (M-23.08 versus 23.30).

An independent t-test analysis revealed that the mean score of Intrinsic Leisure Motivation and its sub-dimensions did not statistically differ in rural and urban prospective teachers, $t(90)=1.13$, $\mathrm{p}=.261$. However, the rural prospective teacher had a mean score more than the prospective urban teacher $(M=91.73$ versus $M=89.44)$. Therefore the null hypothesis 'there will be no significant difference in the mean score of Intrinsic Leisure Motivation (with its respective sub-dimensions) between rural and urban prospective teachers' is accepted.

\section{Major Findings of the study}

* In the Intrinsic leisure motivation scores of prospective teachers, the sub-dimensions dimensions like self-determination, challenge and competence had almost the same highest while commitment had the least mean.

* There exists no significant relationship between intrinsic leisure motivation and academic achievement. Among the four dimensions, competence shared the strongest significant positive correlation with intrinsic leisure motivation and commitment shared the least significant relationship.

* The findings showed that the prospective male teachers had a relatively high score on subdimensions of ILM than the female counterparts. The difference in the average score of the male and female remained constant in the three sub-dimension self-determination, challenge, commitment were male had the edge over the prospective female teachers. In commitment subdimension, the difference in the average was more evident between prospective male and female teachers.

* The findings revealed a significant difference in the mean scores of Intrinsic Leisure Motivation (with its respective sub-dimensions) between prospective female and male teachers. The results showed that the prospective male teachers had a relatively high score on the Intrinsic Leisure Motivation scale than prospective female teachers. When the sub-dimensions were investigated, it was observed that prospective male teachers had scored more than prospective female teachers in all the sub-dimensions with a similar mean difference. The only dimension in which the mean difference between prospective male and female teachers was the highest was the Commitment sub-dimension.

* The result also revealed that, even though the null hypothesis was accepted, the rural prospective teachers had a relatively high score on the Intrinsic Leisure Motivation scale than that of prospective urban teachers. When the sub-dimensions were further analysed, it was observed that rural prospective teachers had scores higher than prospective urban teachers in all the sub-dimensions-Self-determination, Commitment and Challenge except in Competence where both the sub-samples scored similar average.

\section{Discussion Based on Major Findings of the study}

The study's main objective was to explore the relationship between Intrinsic Leisure Motivation (with its sub-dimensions) and academic achievement among prospective teachers. Besides, it also intended to comprehensively examine the Intrinsic Leisure Motivation (with its sub-dimensions) in prospective teachers. The analysis revealed that the Intrinsic Leisure Motivation scores of prospective teachers had high scores above the average. It is also apparent from the result that leisure which displays a high degree of wilfulness, conveys competence feedback and which stretches one's limits to provide novel and challenging stimuli, is sustainable. Commitment sub-dimension was the lowest score in this sample. The prospective teachers had a low dedication to leisure in their lives. A blog written by Dr Jeny Rapheal (2019) wrote 'Why teachers need leisure time' in this article, she listed the common factors which affect the teacher's choice of leisure activities is categorized as institutional factors which is responsible for providing opportunities for teachers to enhance and upgrade their expertise during leisure time is an outlet for a temporary escape from the hassles of the classroom by spending time in gossiping, chatting, sleeping, listening to music and getting glued on social media, which does not require commitment. Jacobson (1995), in his article, stated that while monetary incentive plans assume that teachers will work harder for more pay, there is a reason to 
believe that many teachers see the opportunity for increased leisure time as a more attractive incentive than money.

Significant differences were observed according to the gender sub-sample. A significant difference was found favouring male prospective teachers in the Intrinsic Leisure Motivation (on sub-dimensions like self-determination, commitment and challenge). Previous studies Gill (1983), Iso-Ahola (1982) and a recent study of Ozdomir (2020) suggested that males and females differ in their motivation for leisure participation. There are findings of Elkins (2004) research which indicated that the male's most important motivational factor was the competing/ mastery factor, and for the female, it was the intellectual dimension. Hickerson \& Beggs (2007) opined that girls are involved in passive leisure time activities that increase boredom, and boys perform active leisure and experience less boredom. They further elaborated that students lack the skills to manage leisure time. Beggs, Elkins, and Powers (2005) emphasized that females were more likely to participate in non-competitive recreational sports programs and activities in which they could avoid conflict.

In the sample under study, prospective female teachers had below average in Intrinsic Leisure Motivation, and also they had significantly low mean score in self-determination, commitment and challenge. A large significant difference was found in commitment sub-dimension. Codina and Pestana (2019) are of the opinion that there are many factors that influence women's evaluation of leisure time, like resilience, time management and how they are critical in choosing their leisure activities. In another study, Kooji et al. (2018) have pointed out that men's future perspectives are focused on work, and women focus on different goals related to work, family and leisure. These differences should be valued concerning why women have a low commitment to their leisure activities because of such distractibility.

Contrary to Ely (2010) study, which highlighted that women seem to take more significant advantage of the time they have available for leisure. Men, on the other hand, pursue their leisure time with a strong desire to make choices based on their needs. They are more inclined to take the risk and select those leisure behaviours that slightly exceed their skills. The commitment dimension was in favour of prospective male teachers, and the reason why dedication to leisure activity is more in prospective male teachers as they seem to be because of the availability of time. Male have time allotted for their work and free time. As far as women are concerned, they have time divided amongst work, family, household chores and the limited free time in those activities which do not demand dedication. The limitation of less available time forces them to be more critical regarding choosing leisure activities. They make decisions that are more valuable by herself. This result is consistent with the findings of Codina and Pestana research.

Another finding of this study was that no significant difference in the mean score of prospective teachers belonging to rural and urban locality. But on closer analysis, it was found that prospective teachers of the rural locality had a higher average than the prospective urban teachers, and they scored a high average on sub-dimensions like self-determination. commitment and challenge. It was only in the 'competence' dimension that prospective rural and urban teachers had similar averages. In keeping with this, the empirical investigation by Sjolie and Thuen (2002) concluded that both rural and urban adolescents spent more time in sedentary activities like watching TV/video and playing TV/data games. No difference was observed between the two groups regarding activity patterns. The study suggested that access to cycling tracks and walking trails in residential areas may increase both walking and cycling to school and leisure activities. And this opportunity was observed more in a rural setting than in an urban environment.

Another fascinating contrary study by Wilcox et al. (2000) reported that rural women faced more barriers to leisure-time physical activity than urban women faced obstacles. Rural women stated that fear of injury, lack of a safe place of exercise and caregiver duties interfered in pursuing leisure activities. In contrast, urban women listed their top barriers to leisure-time physical activity suggested that green space may be significant environmental factors influencing leisure-time physical activity. And the present scenario of urbanization and encroachment of green patches in rural areas may be the reason why both rural and urban youth are 
not inclined towards leisure activities because of the lack of green spaces.

Contrary to the study by Roemmich et al. (2018), which stated that rural youth and adults are less likely to engage in leisure-time physical activities compared to urban and suburban adults. Becker et al. (2014) opined that park use of those living in rural and urban communities might be anticipated to differ based on potential cultural difference.

The main objective of this study was to examine the relationship between Intrinsic Leisure Motivation (with its respective sub-dimensions) and academic achievement among prospective teachers. It was found that the sample under study did not share a meaningful relationship between Intrinsic Leisure Motivation (with its respective sub-dimensions) and academic achievement. The review of related literature affirmed that several studies had evaluated the association of leisure activities and leisure time with other variables (Gardner, 2011; Shernoff, 2010; Eccles, 2011; Sauerwein, 2016). Few reviews have been conducted using intrinsic leisure motivation as the variable under study (Larson, 2000; Ozdemir, 2020; Hansen \& Larson, 2003). Studies like Demers (2015) proved that those with successful career paths indulged in active leisure activities. Students use recreational activities as a mechanism to cope with the demands of university life (Iso-Ahola, 1989). In yet another research Iffat (2018) indicated that students who spend an average of 2 hours per day on leisure activities scored better in academics. However, this study did not agree to a significant impact of Leisure time activity on Academic Achievement. In fact the relationship is not strong, and the Academic Achievement is affected by some other variables as well. The result contradicts findings from Feldman and Matjaska (2007) who reported a positive connection between participation in multiple leisure activities and good grades.

The findings of Caldwell and Witt (2011) research is steady with this particular research finding in the sense that active leisure did contribute to the overall development and positive outcomes in personal, social and emotional areas of an individual. However, they did not specifically cover the area of school achievement. Leisure time in India has been viewed from different perspectives. It has been reported in studies of Taagney (1988) and Congo (2015) that adolescents engage in sedentary activities such as watching TV, listening radio, playing online games, using social media, internet surfing etc. They are involved in too many passive leisure activities, which do not contribute to this overall youth development. In particular, more recent studies by Syvaija (2014) and Van Dijk (2014) using measured physical activity have tended either to find no association between physical activity and academic achievement. Even negative associations were found between physical activity and academic achievement in studies like Van Dijk (2014) and Esteban-Cornejo (2014). A comprehensive longitudinal study of Sari Aaltonen et al. (2016) propounded that leisure-time physical activity predicting academic achievement was not apparent, and no evidence was found in any of their surveys. However, the study explained the cognitive ability as being associated with academic attainment and leisure-time physical activity in young adulthood as an independent association between physical activity and academic achievement.

Payne (1991) differentiated the complexity of the relationship between adult education and leisure in three ways: adult education as (a) a leisure form, (b) preparation for leisure, and (c) activity from which adults learn. Emergent themes in this study represented each of these aspects.

Respondents engaged in adult leisure learning courses indicated that their motivations were oriented toward social and cognitive motives rather than professional and educational motives. Informants identified that the value of participation for them was to stimulate or enhance their creativity, enhance their lives, gives them an opportunity to try new things, and reduce stressful life elements.

\section{Educational Implications of the Study}

Motivation plays a crucial role in a teacher's pedagogy. As a pre-service teacher, it is crucial to think about the ways students can be intrinsically motivated in the classroom. Teachers can empower and move their students through providing a supportive, quality learning environment, where learning is achievable and supported by both teachers and students.

$\square$ Increasing the number of leisure time, space, and activities have great importance for our future. Recreation activities should be 
encouraged to prevent children and young people from entering into aberrant behaviours and providing social integration.

Teachers are role models for students; teachers who exhibit their passion and enthusiasm for learning will transfer these attributes to the classroom, developing intrinsic students. Motivating students into learning for the desire of learning can open up a world of possibilities.

$\square$ Intrinsic motivation is a fundamental element in students' learning. Teachers influence learning experiences that allow students to see knowledge as worthwhile and take ownership of their learning.

School experience can create leisure interests through continuing motivation(when students become so interested in a classroom topic that they then pursue it on their own, outside of school.

School experience that creates leisure interests encourages students to learn or practice content related to school or that are cognitively demanding to show a positive relationship with school achievement. It could benefit generalizing habits of discipline, self-regulation, problem-solving, and these are directly related to academic achievement.

Many researchers emphasized that the sources of intrinsic motivation are particularly relevant because it is important to know how to improve intrinsic motivation in applied settings. Leisure motivations, both intrinsic and extrinsic, are in direct relation with leisure and recreation opportunities and programs on campus. Understanding what motivates student participation in campus recreational programs may qualify campus recreation professionals to design better programs that maximize student activity. Therefore, by identifying individuals' motivations for an activity, professionals can use this knowledge to create awareness on an individual level but also help the community. Hence, leisure motivation and its relationship to other factors should be studied further.

According to the investigators' opinion, it would be interesting to investigate whether other variables or processes influence women's evaluations of their leisure time, such as resilience, adaptive capacity, time management, and the fact that they are more critical when choosing their leisure activities. Also, considering that Kooij, Kanfer, Betts, and Rudolph (2018) have recently seen that the future perspectives of men are more focused on work and women focus on different goals related to work, family, and leisure, we think that these differences should be valued in relation to different areas of activity of the person. These findings underscore the importance of motivation in the everyday life of individuals and provide potential insights for the conduct of future research in this area.

\section{CONCLUSION}

When comparing the results of various studies, it is essential to keep in mind that both physical leisure activity and academic performance are complex to define and can be measured in many ways. It can be speculated that from positive association to no association and even to negative association between the variable could be because of the difference in the schooling system and the different perspectives one has regarding leisure activity. The small sample size limits the finding of this study. A vital strength of the present study is the variable Intrinsic Leisure Motivation studied among prospective teachers. It will pave the way to suggest the need to motivate future prospective teachers in pursuing leisure activities to enhance their capabilities and overall development in their professional life. This study did not clearly support the belief that those adults who have high Intrinsic Leisure Motivation performed better in academics. However, it did support that Intrinsic Leisure Motivation was more profound in male as compared to female. And the adults belonging to rural locality had elevated Intrinsic Leisure Motivation than the urban residential adults.

\section{REFERENCES}

Amabile, T.M., Hennessey, B.A. and Grossman, B.S. 1986. Social influences on creativity: The effects of contractedfor reward. J. Personality and Social Psychology, 50(1): 14-23.

Beggs, B.A., Elkins, D.J. and Powers, S. 2005. Overcoming barriers to participation in campus recreational sports. Recreational Sports J., 29(2): 143-155.

Beggs, B.A. Stitt, J.E. and Elkins, D.J. 2004. Leisure Motivation of Participants and Nonparticipants in Campus Recreational Sports Programs. Recreational Sports J., 28(1): 65-77.

Broh, B.A. 2002. Linking Extracurricular Programming to Academic Achievement: Who Benefits and Why? Socio. of Edu., 75(1): 69-95. 
Codina, Nuria; Pestana, José V. 2019. Time Matters Differently in Leisure Experience for Men and Women: Leisure Dedication and Time Perspective. Int. J. Environ. Res. Public Health, 16(14): 2513.

Deci, E.L. and Ryan, R.M. 1985. Intrinsic motivation and selfdetermination in human behaviour. New York: Plenum Press.

DeMers, J. 2015. Seven ways successful people spend their free time. Retrieved from http://www.inc.com/jayson-demers/7ways-successful-people-spend-their-free-time.html

Eccles, J.S. and Roeser, R.W. 2011. Schools as Developmental Contexts During Adolescence. J. Res. Adolescence, 21(1): 225-241.

Elkins, D.J. 2004. Level of perceived constraint: A comparative analysis of negotiation strategies in campus recreational sports (Doctoral dissertation). Indiana University, Bloomington.

Elliot, A.J. and McGregor H.A. 2001. A 2x2 achievement goal framework. J. Personality and Soc. Psychology, 80: 501-519.

Ely, R. and Mercurio, A. 2010. Time perspective and autobiographical memory: Individual and gender differences in experiencing time and remembering the past. Time Soc., 20: 375-400.

Feldman, A. and Matjasko, J. 2007. Profiles and portfolios of adolescent school-based extracurricular activity participation. J. Adolescence, 30(2): 313-332.

Freud, S. 1962. The ego and the id. New York: Norton. (Original work published 1923).

Garbarino, J. 1975. The impact of anticipated reward upon cross-age tutoring. J. Personality and Soc. Psychology, 32(3): 421-428.

Gardner, M., Roth, J. and Brooks-Gunn, J. 2011. Sports Participation and Juvenile Delinquency: The Role of the Peer Context Among Adolescent Boys and Girls With Varied Histories of Problem Behaviour. Sport, Exercise, and Performance Psychology, 1: 19-37.

Grolnick, W.S. and Ryan, R.M. 1987. Autonomy in children's learning: An experimental and individual difference investigation. J. Personality and Soc. Psychology, 52(5): 890-898.

Hansen, D., Larson, R.W. and Dworkin, J. 2003. What Adolescents Learn in Organized Adolescent Activities: A Survey of Self-Reported Developmental Experiences. J. Res. on Adolescence, 13(1): 25-55.

Hickerson, B.D. and Beggs, B.A. 2007. Leisure time boredom: issues concerning college students. College Students Journal, 41(4).

Hull, C.L. 1943. Principles of behavior. New York: AppletonCentury-Crofts.

Iffat, K. 2018. Relationship between Leisure Time Activities and Academic Achievement: An Indian Perspective. J. Adv. Scholarly Res. Allied Edu. [JASRAE], 15(12).

Iso-Ahola, S.E. 1989. Motivation for Leisure. In E. Jackson \& T. Burton (Eds.), Understanding leisure and recreation: Mapping the past, charting the future (pp. 247-279). State College, PA: Venture.
Jacobson, S. 1995. 'Monetary Incentives and the Reform of Teacher Compensation: A Persistent Organizational Dilemma', Int. J. Edu. Reform, 4(1): 29-35.

Jeny, R. 2019. Retrieved from https://timesofindia.indiatimes. com/readersblog/let-us-think/why-teachers-need-leisuretime-2698/

Kooij, D.T.A.M., Kanfer, R., Betts, M. and Rudolph, C.W. 2018. Future time perspective: A systematic review and metaanalysis. J. Appl. Psychology, 103(8): 867-893.

KoojiDorien T.A.M. Kooij, Annet H. de Lange, Paul G.W. Jansen and Josje S.E. Dikkers. 2013. Beyond chronological age. Examining perceived future time and subjective health as age-related mediators in relation to work-related motivations and well-being, Work E Stress, 27(1): 88-105.

Larson, R.W. 2000. Toward a Psychology of Positive Adolescent Development. Am. Psychologist, 55(1): 170-183.

Larson, R., Hansen, D. and Moneta, G. 2006. Differing Profiles of Developmental Experiences across Types of Organized Adolescent Activities. Dev. Psychology, 42(5): 849-863.

Malone, T.W. and Lepper, M.R. 1987. Making Learning Fun: A Taxonomy of Intrinsic Motivations for Learning. In: Snow RE, Farr MJ, ed. Aptitude, Learning, and Instruction: Iii. Conative and Affective Process Analysis. Hillsdale, New Jersey: Erlbaum.

McClelland, D. C. 1961. The achieving society. Princeton, NJ: Van Nostrand. McClelland, D. C. (1975). Power: The inner experience. New York: Irvington.

McClelland, D. C., Atkinson, J. W., Clark, R.A. and Lowell, E. L. 1953. The achievement motive. New York: AppletonCentury-Crofts.

Özdemir, A.S., Büyüköztürk, Ş. and Karaküçük, S. 2016. Explaining destination choices based upon recreational opportunities through intrinsic and extrinsic travel motivations. J. Human Sci., 13(2): 3002-3021.

Ozdomir. 2020. Exploring Intrinsic Leisure Motivations of University Students. Eu. J. Edu. Stu., 7(1): 52-65.

Payne, J.H. 1991. Understanding adult education and leisure. Leisure Stu., 10(2): 149-162.

Ramos, W.D., Anderson, A.R. and Lee, D. 2018. Collegiate Club Swimming: An Examination of Leisure Motivations. Recreational Sports J., 42(1): 75-89.

Roemmich, J. N., Johnson, L., Oberg, G., Beeler, J. E., \&Ufholz, K.E. 2018. Youth and Adult Visitation and Physical Activity Intensity at Rural and Urban Parks. Int. J. Environ. Res. Pub. Heal., 15(8): 1760.

Ryan, R. and Deci, E. 2007. Active human nature: Selfdetermination theory and the promotion and maintenance of sport, exercise, and health. In Intrinsic motivation and self-determination in exercise and sport, Edited by: Hagger, M. and Chatzisarantis, N. 1-21. Champaign, IL: Human Kinetics.

Ryan, R.M. and Deci, E.L. 2000. Self-determination theory and the facilitation of intrinsic motivation, social development, and well-being. Am. Psychologist, 55(1): 68-78. 
Ryan, R. M., Connell, J. P. and Deci, E. L. 1985. A motivational analysis of self-determination and self-regulation in education. In C. Ames \& R. E. Ames (Eds.), Research on motivation in education: The classroom milieu (pp. 13-51). New York: Academic Press.

Sari Aaltonen, Antti Latvala, Richard J. Rose, Urho M. Kujala, Jaakko Kaprio and Karri Silventoinen. 2016. LeisureTime Physical Activity and Academic Performance: Cross-Lagged Associations from Adolescence to Young Adulthood. Scientific Reports, 6: 39215.

Sauerwein, M., Désirée Theis and Natalie, F. 2016. How Youths' Profiles of Extracurricular and Leisure Activity Affect Their Social Development and Academic Achievement. IJREE., 4(1): 103-124.

Sjolie, A.N. and Thuen, F. 2002. School journeys and leisure activities in rural and urban adolescents in Norway. Heal. Promotion Int., 17(1): 21-30.

Skinner, B.F. 1953. Science and human behavior. New York: Macmillan.

Syvaoja, H. J., Tammelin, T. H., Ahonen, T., Kankaanpaa, A. and Kantomaa, M.T. 2014. The associations of objectively measured physical activity and sedentary time with cognitive functions in school-aged children. PLoS One. 9: e103559.
Weiner, B. 1992. Human Motivation: Metaphors, Theories and Research, Newbury Park, CA: Sage.

Weissinger, E. and Bandalos, D. 1995. Development, reliability and validity of a scale to measure intrinsic motivation in leisure. J. Leisure Res., 27: 379-400.

Weissinger, E. and Iso-Ahola, S.E. 1984. Intrinsic leisure motivation, personality and physical health. Society and Leisure, 7: 217-228.

Wilcox, S., Castro, C., King, A.C., Housemann, R. and Brownson, R.C. 2000. Determinants of leisure time physical activity in rural compared with urban older and ethnically diverse women in the United States. J. Epidemiol. Community Heal., 54(9): 667-72.

Winter, D.G. 1998. “Toward a science of personality psychology": David McClelland's development of empirically derived TAT measures. History of Psychology, 1(2): 130-153. 
